\title{
Pharmacovigilance in Low and Middle-Income Countries: A review with particular focus on Africa
}

\author{
Ronald Kiguba ${ }^{1}$, Sten Olsson ${ }^{2}$, and Catriona Waitt ${ }^{3}$ \\ ${ }^{1}$ Makerere University College of Health Sciences \\ ${ }^{2}$ Sten Olsson Pharmacovigilance Consulting \\ ${ }^{3}$ University of Liverpool
}

September 25, 2021

\begin{abstract}
Low- and middle-income countries (LMIC) face unique challenges with regard to the establishment of robust pharmacovigilance systems capable of generating data to inform healthcare policy and practice. These include the limited integration and reliance of pharmacovigilance systems across LMIC despite recent efforts to harmonize pharmacovigilance rules and regulations in several regional economic communities; the need to translate reporting tools into numerous local languages; low numbers of healthcare providers relative to number of patients, with very short consultation times; scarcity of well-trained pharmacovigilance personnel with little or no budgetary support for these activities from national governments; high turnover of pharmacovigilance staff whose training involves a substantial amount of resources; little awareness of pharmacovigilance among healthcare workers, decision makers and consumers; very low spontaneous reporting rates with poor quality reports which hinders robust signal detection analyses; little collaboration between public health programmes and national medicines regulatory authorities; limited investment in pharmacovigilance activities especially during mass drug administration for neglected tropical diseases; high uptake of herbal and traditional medication, mostly by self-medication; disruptive political conflicts jeopardizing fragile systems; and little or no access to drug utilization data which makes it difficult to reliably estimate the true safety risks of medicine use. This review summarises the specific challenges and areas of progress in pharmacovigilance in LMIC with special focus on the situation in Africa.
\end{abstract}

\section{Hosted file}

PV_LMIC Review Submission_FINAL.docx available at https://authorea.com/users/437347/articles/ 539047-pharmacovigilance-in-low-and-middle-income-countries-a-review-with-particularfocus-on-africa 

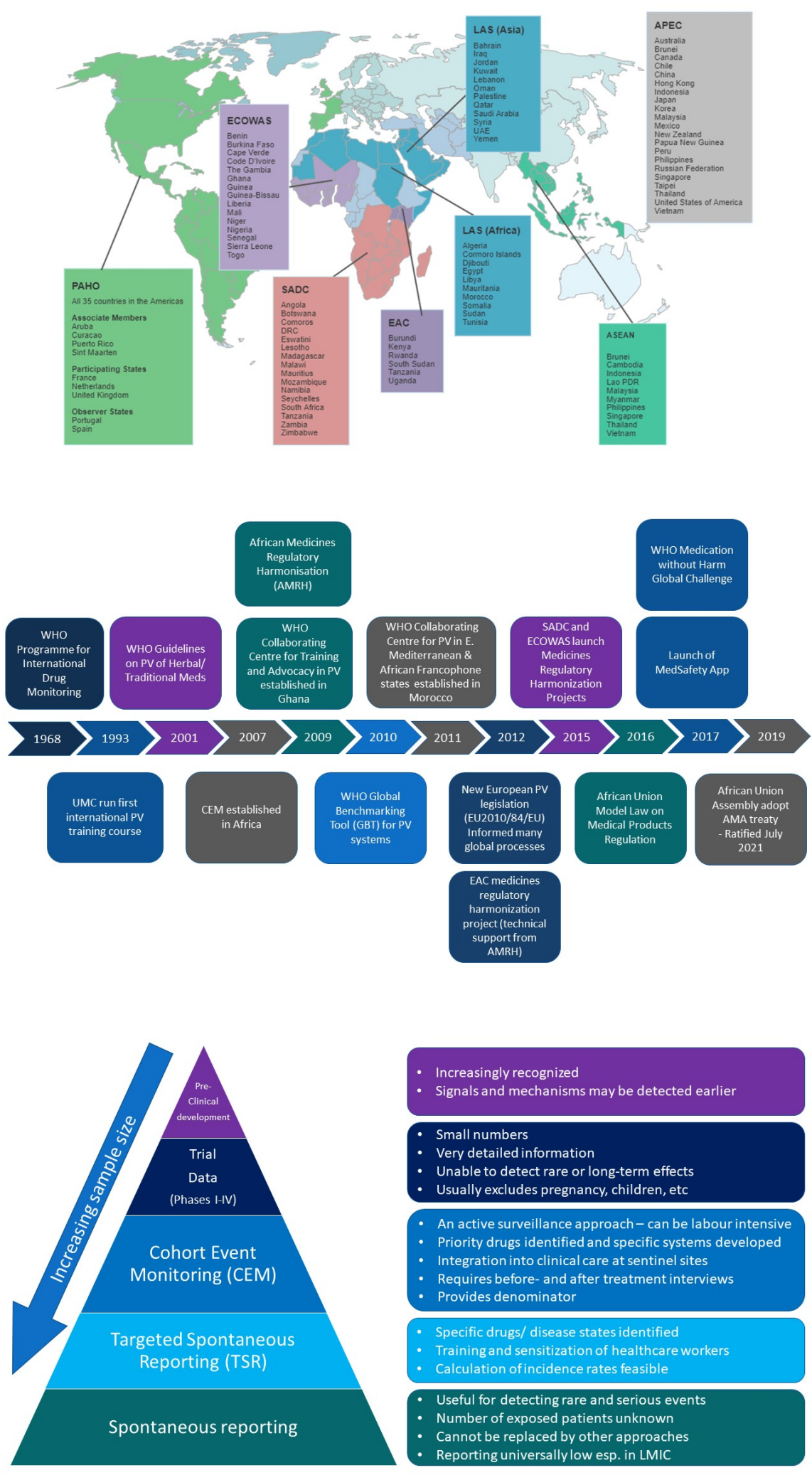

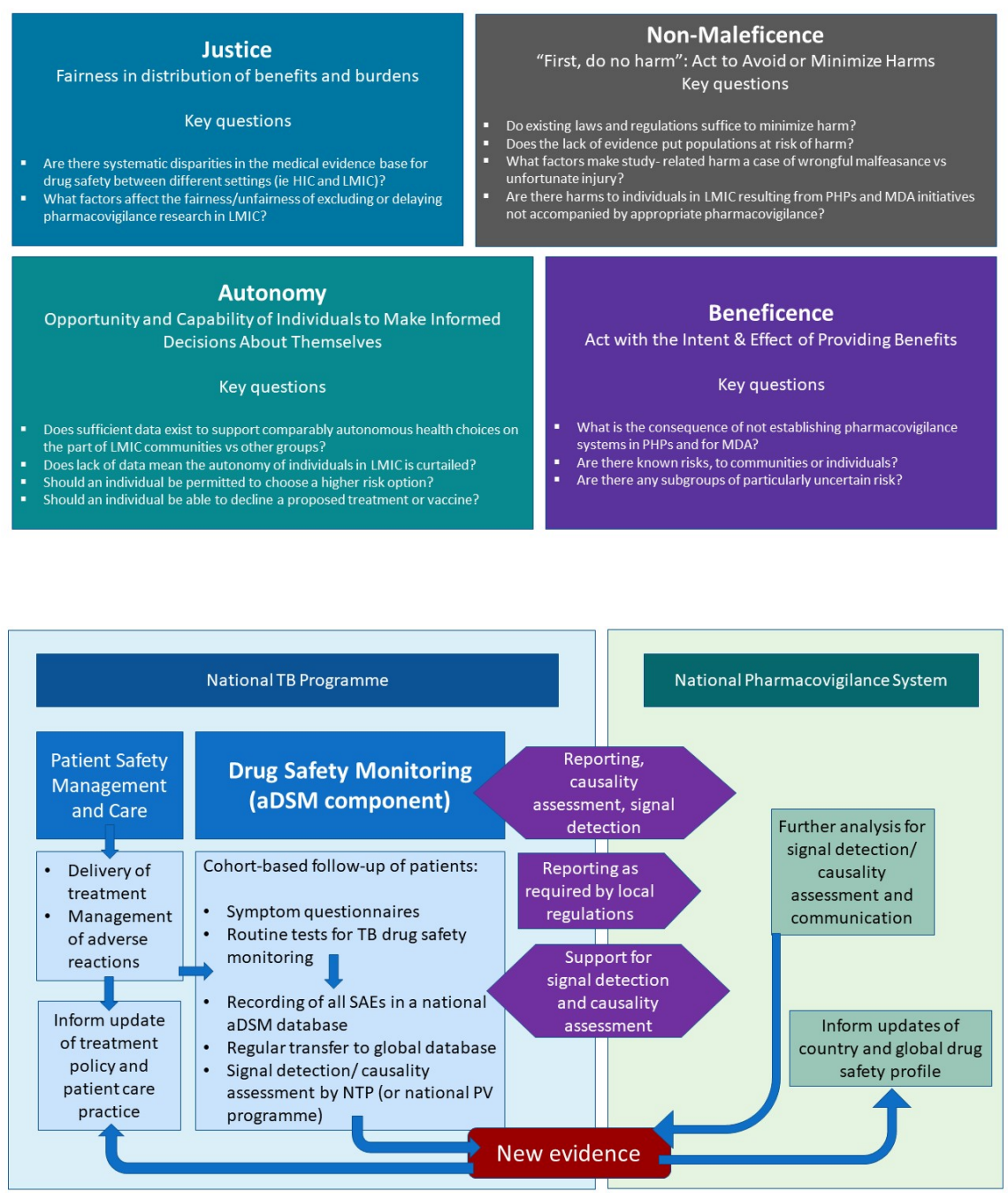